\title{
Mobile Cryogenic Vessel
}

National Cancer Institute

\section{Source}

National Cancer Institute. Mobile Cryogenic Vessel. NCI Thesaurus. Code C149661.

A mobile thermally insulated container designed to maintain the contents in a liquid state. 